\title{
ОЦІНКА ЗМІН ГЕМОДИНАМІКИ У ПОСТРАЖДАЛИХ ВІЙСЬКОВОСЛУЖБОВЦІВ ІЗ МІННО- ВИБУХОВИМИ ПОРАНЕННЯМИ В ПРОЦЕСІ АЕРОМЕДИЧНОЇ ЕВАКУАЦІЙ
}

\author{
Г.П. Хитрий, Ю.Д. Ухач
}

Українська військово-медична академія, м. Київ, Україна

Вступ. Швидка медична евакуація шляхом аероевакуації до місць надання кваліфікованої та спеціалізованої медичної допомоги стала більш ефективною з часів Другої світової війни та визнана ефективною у спроможності "очищення поля бою" та прискорення евакуації постраждалих до лікарень та клінічних центрів. Тим не менше, вплив аеромедичної евакуації на пацієнтів з політравмою все ще недостатньо зрозумілий, особливо у випадку масової евакуації, коли широкому колу пацієнтів може знадобитися сортування в суворих або екстремальних умовах із обмеженою доступністю.

Мета роботи. Оцінити гемодинамічні зміни під час проведення аеромедичної евакуації у постраждалих із політравмою та із проникаючими пораненнями голови.

Матеріали та методи. Проведено ретроспективний аналіз карт інтенсивної терапї 32 поранених та травмованих військовослужбовців, яким проводилася аеромедична евакуація із зони проведення АТО/OОС протягом 2017-2018 рр.

Результати. На першому етапі дослідження було встановлено, що рівень САТ на наземному етапі

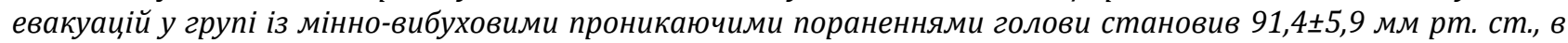
той час як у постраждалих із мінно-вибуховими пораненнями живота та/або грудної клітки він був значно

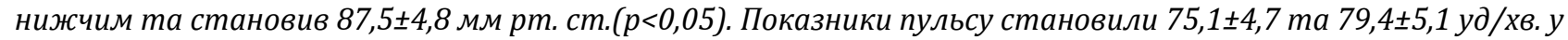
досліджуваних групах відповідно (p<0,05). На другому етапі дослідження встановлено статистично достовірне зниження показників гемодинаміки та наростання ЧСС у постраждалих обох груп у порівнянні

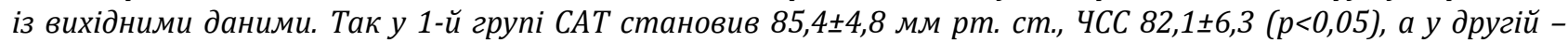
$82,7 \pm 4,9$ мм рт. ст., ЧСС 86,2 $\pm 5,8$ (p<0,05). На подальших етапах (20 та 40 хвилина) аеромедичної евакуації відмічалась поступова стабілізація гемодинаміки. На завершальному етапі евакуації в обох досліджуваних групах показники ЧСС та САТ знаходилися в межах значень, отриманих на наземному етапі.

Висновки. В результаті проведеного дослідження встановлено, що на другому етапі дослідження (підйом на висоту) спостерігалися достовірні зміни гемодинамічних показників, які проявлялися гіпотензією та тахікардією (p<0,05), які поступово були медикаментозно кореговані, та починаючи з 3 етапу (20 хв.) повернулися до вихідних значень в обох досліджуваних групах. У постраждалих із мінновибуховими пораненнями живота та/або грудної клітки на 4-му етапі дослідження спостерігалося зниження САТ, що може вказувати на більшу гемодинамічну нестійкість у даній досліджуваній групі.

Ключові слова: аеромедична евакуація, середній артеріальний тиск, зміни гемодинаміки.

Вступ. Аеромедична евакуація (AE) являє собою комплекс заходів, спрямованих на транспортування травмованих та хворих військовослужбовців на вищі етапи надання медичної допомоги за допомогою спеціалізованих чи пристосованих літальних засобів [1]. Швидка медична евакуація шляхом аероевакуації до місць надання кваліфікованої та спеціалізованої медичної допомоги стала більш ефективною 3 часів Другої світової війни та визнана ефективною у спроможності "очищення поля бою" та прискорення евакуації постраждалих до лікарень та клінічних центрів [2, 3].

Однак аеромедична евакуація не рекомендується для всіх поранених, і існують повідомлення, що повітряний транспорт погіршує складні наслідки травми [4,5]. Наприклад, органи, наповнені повітрям, такі як травмовані легені або кишечник, можуть постраждати від додаткової травми через швидке розширення газів на більшій висоті [1]. Розширення газу внаслідок гіпобарії під час AE, в тому числі зменшення парціального тиску кисню може погіршити стан пацієнтів, які перебувають в стані гіпоксії або пацієнтів після перенесеної значної крововтрати. Також повідомлялося про погані результати у хворих на комбіновану черепно-мозкову травму та політравму $[5,6]$.

Тим не менше, вплив $\mathrm{AE}$ на пацієнтів 3 політравмою все ще недостатньо зрозумілий, особливо у випадку масової евакуації, коли широкому колу пацієнтів може знадобитися сортування в суворих або екстремальних умовах із обмеженою доступністю [2, 3].

Мета дослідження: оцінити гемодинамічні зміни під час проведення аеромедичної евакуації у постраждалих із політравмою та із проникаючими пораненнями голови. 
Матеріали та методи. Проведено ретроспективний аналіз карт інтенсивної терапії 32 поранених та травмованих військовослужбовців, яким проводилася $\mathrm{AE}$ із зони проведення АТО/ООС протягом 20172018 рр. Постраждалих в залежності від типу отриманих поранень було розділено на 2 групи. До першої досліджуваної групи ввійшло 15 військовослужбовців із мінно-вибуховими проникаючими пораненнями голови. До другої досліджуваної групи увійшло 17 військовослужбовців із мінно-вибуховими пораненнями живота та/або грудної клітки. Кваліфікована медична допомога, невідкладні оперативні втручання та стабілізація стану постраждалих відбувалася на етапі перебування в мобільних госпіталях. $\mathrm{AE}$ проводилася санітарним гелікоптером Мi-8 за невідкладними показаннями на етап спеціалізованої медичної допомоги при досягненні критеріїв транспортабельності. Анестезіологічний супровід і заходи інтенсивної терапії проводилися у повному об’ємі спеціалізованою анестезіологічною бригадою у складі лікаря-анестезіолога та медичної сестри-анестезиста.

3 метою оцінки гемодинамічних змін проводився безперервний моніторинг артеріального тиску (AT) та частоти серцевих скорочень (ЧСС) апаратом Prizm 3 NST (Hеасо Inc, GB). Показники середнього артеріального тиску (САТ) було розраховано за загальноприйнятою методикою.

Методологію дослідження було побудовано на системному підході. Аналіз гемодинамічних змін проводився на наступних етапах евакуації: 1) вихідні дані, отримані під час наземного етапу транспортування; 2) етап підйому на висоту (взліт); 3) 20 хв. евакуації; 4) 40 хв. евакуації; 5) етап приземлення.

Статистичне опрацювання даних проводили в програмному середовищі SPSS Statistics 25.0.0 (IBM Corporation, 2018). При обробці результатів досліджень використовувалися критерії $\chi 2$ - Пірсона і t Стьюдента.

Результати дослідження та їх обговорення: Постраждалі дослідних груп не мали статистично значущої різниці за віком, тривалість евакуації в обох групах становила $59,4 \pm 13,4$ хвилин. Водночас 15 постраждалих 3 1-ї досліджуваної групи (100\%) та 12 постраждалих з 2-ї групи (70,5\%) потребували ШВЛ та отримували медикаментозну седацію в процесі транспортування. На першому етапі дослідження було встановлено, що рівень САТ на наземному етапі евакуацій у групі із мінновибуховими проникаючими пораненнями голови становив $91,4 \pm 5,9$ мм рт. ст., в той час як у постраждалих із мінно-вибуховими пораненнями живота та/або грудної клітки він був значно нижчим та становив $87,5 \pm 4,8$ мм рт. ст. $(\mathrm{p}<0,05)$. Показники пульсу у досліджуваних групах відповідно становили $75,1 \pm 4,7$ та $79,4 \pm 5,1$ уд/хв. $(\mathrm{p}<0,05) . \quad$ Дані результати вказують на більш значимий рівень крововтрати в постраждалих другої групи, а також на необхідність підтримки керованої гіпотензії [7,8]. На другому етапі дослідження встановлено статистично достовірне зниження показників гемодинаміки та збільшення ЧСС у постраждалих обох груп у порівнянні із вихідними даними. Так у 1-й групі САТ становив $85,4 \pm 4,8$ мм рт. ст., ЧСС $82,1 \pm 6,3$ ( $<<0,05)$, а у другій - відповідно $82,7 \pm 4,9$ мм рт. ст. i $86,2 \pm 5,8(\mathrm{p}<0,05)$. На подальших етапах $(20$ та 40 хвилина) аеромедичної евакуації нами спостерігалася поступова стабілізація гемодинаміки (рис.1) що було обумовлено зменшенням впливу несприятливих факторів польоту (прискорення, акселераційний стрес та ін.) [1], а також проведеними заходами щодо стабілізації постраждалих на борту гелікоптера [7]. Порівнюючи показники САТ в групі постраждалих із мінно-вибуховими проникаючими пораненнями голови було встановлено, що починаючи з 3-го етапу і до завершення аеромедичної евакуації, стан гемодинаміки практично наблизився до рівня наземного етапу, а різниця між вихідними показниками була статистично недостовірною ( $>0,05)$.

Водночас у постраждалих із мінновибуховими пораненнями живота та/або грудної клітки на 4-му етапі дослідження (40 хвилина) мало місце зниження гемодинаміки (рис.1), що могло бути обумовлено реакцією на введення наркотичних анальгетиків 3 метою знеболення $(\mathrm{p}<0,05)$.

Аналізуючи показники ЧСС $\mathrm{y}$ постраждалих на 3-5 етапах евакуації (рис.2) було встановлено, що вони статистично не відрізнялися між собою ( $>>0,05)$. 


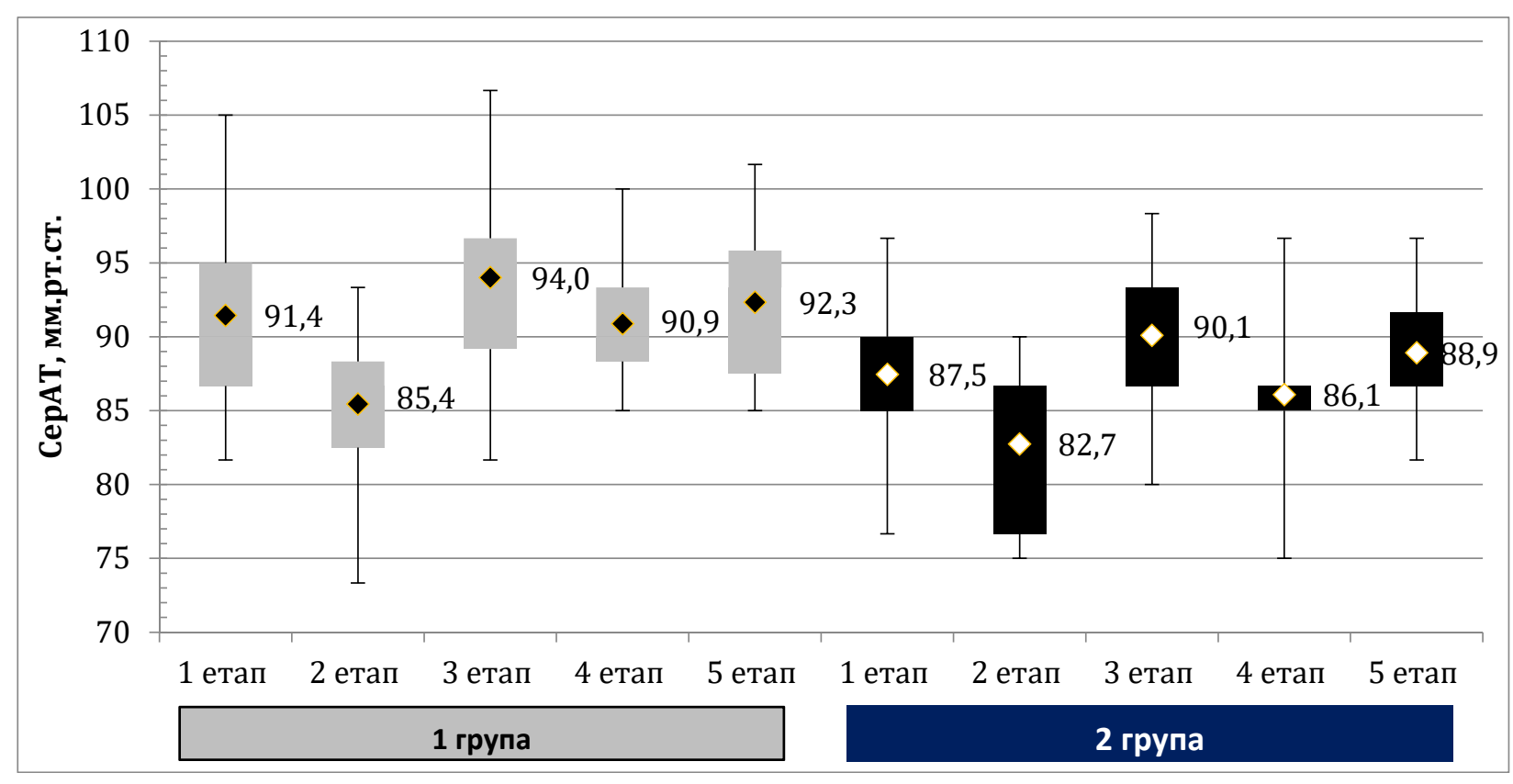

Рисунок 1. Зміни САТ у постраждалих першої та другої досліджуваних груп на етапах аеромедичної евакуації.

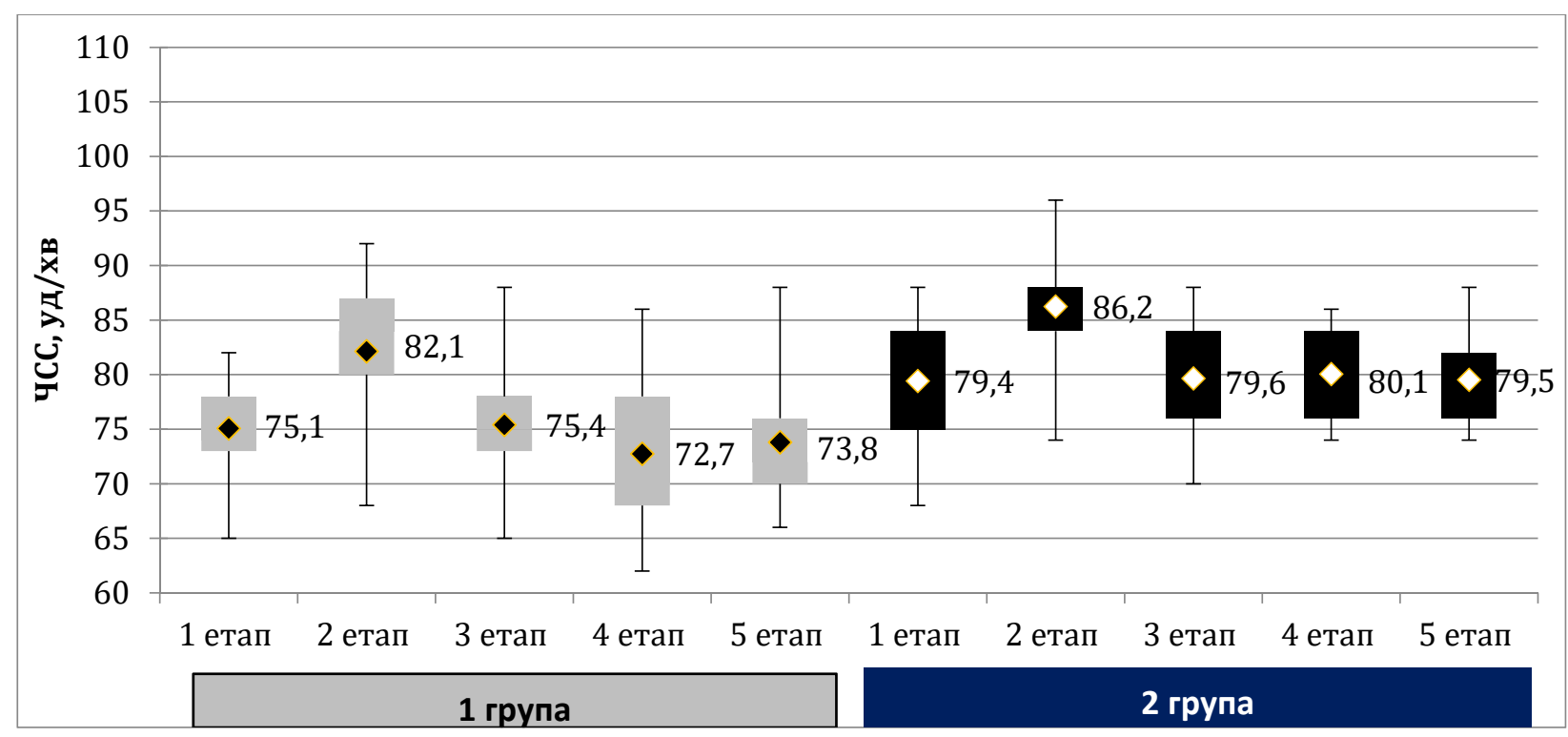

Рисунок 2. Зміни ЧСС у постраждалих першої та другої досліджуваних груп на етапах аеромедичної евакуації.

В обох досліджуваних групах на завершальному етапі аеромедичної евакуації показники ЧСС та САТ знаходилися в межах значень, отриманих на наземному етапі, що вказує на ефективність заходів безперервної

\section{Висновки}

1. Аналіз світових джерел інформації щодо організації та особливостей проведення аеромедичної евакуації військовослужбовців, а також досвід набутий в умовах ведення збройних конфліктів, підтвердив їі дієвість і ефективність та дозволив обгрунтувати потребу в подальших дослідженнях щодо інтенсивної терапії, які проводилися спеціалізованою анестезіологічною бригадою на борту гвинтокрила.

покращення заходів моніторингу та безпеки транспортування у відповідності до вимог стандартів НАТО.

2. В результаті проведеного дослідження було встановлено, що на другому етапі дослідження (підйом на висоту) спостерігалися достовірні зміни гемодинамічних показників, що проявлялися 
гіпотензією та тахікардією $(\mathrm{p}<0,05)$, які поступово були медикаментозно кореговані, та починаючи із 3 етапу (20 хв.) повернулися до вихідних значень в обох досліджуваних групах.

3. У постраждалих 3 мінно-вибуховими пораненнями живота та/або грудної клітки на 4-му етапі дослідження спостерігалося зниження САТ, що за часом збігалося із введенням наркотичних анальгетиків і може

\section{Література}

1. А.І. Єна, І.А. Лурін, В.В. Кравчук та ін Аеромедична евакуація : навч. посіб. - Тернопіль : ТДМУ, 2010. - 192 c.

2. Joshi MC, Sharma RM: Aero-medical considerations in casualty air evacuation (CASAEVAC). Med J Armed Forces India 2010; 66(1): 63-5.

3. Bradley M, Nealeigh M, Oh JS, Rothberg P, Elster EA, Rich NM. Combat casualty care and lessons learned from the past 100 years of war. Curr Probl Surg. 2017; 54(6):315-351.

4. Fiskum GPJ, Medina J, Rangghran P, Coksayan T, Gullpalli R, Kozar R. Mechanism by which aeromedicalevacuation relevant hypobaria worsens mortality followng polytrauma. [Abstract.] Aerosp Med Hum Perform. 2019; 90(3):196.

\section{References}

1. Ena, A.I., Lurin, I.A., Kravchuk, V.V. and others (2010). Aeromedychna evakuatsiia: textbook. Ternopil: TSMU, 192 p. [in Ukrainian].

2. Joshi, M.C., Sharma, R.M. (2010). Aero-medical considerations in casualty air evacuation (CASAEVAC). Med J Armed Forces India. 66(1): 63-5.

3. Bradley, M, Nealeigh, M, Oh JS, Rothberg P, Elster E.A., Rich, N.M. (2017). Combat casualty care and lessons learned from the past 100 years of war. Curr Probl Surg. 54(6):315-351.

4. Fiskum, GP.J., Medina J., Rangghran P., Coksayan T., Gullpalli R., Kozar R. (2019). Mechanism by which aeromedicalevacuation relevant hypobaria worsens mortality followng polytrauma. [Abstract.] Aerosp Med Hum Perform.; 90(3):196.

5. Scultetus, A.H., Haque, A., Chun. S.J., et al (2016). вказувати на більшу гемодинамічну нестійкість у даній досліджуваній групі.

4. Наявність спеціалізованої анестезіологічної бригади на борту гвинтокрила дозволяє забезпечити ефективний моніторинг та заходи інтенсивної терапії в процесі евакуації, а також корегувати дію несприятливих факторів польоту на постраждалого.

5. Scultetus AH, Haque A, Chun SJ, et al: Brain hypoxia is exacerbated in hypobaria during aeromedical evacuation in swine with traumatic brain injury. J Trauma Acute Care Surg 2016; 81(1): 101-7.

6. Skovira JW, Kabadi SV, Wu J, et al: Simulated aeromedical evacuation exacerbates experimental brain injury. J Neurotrauma 2016; 33(14): 1292-302.

7. Daniel Y, Habas S, Malan L, Escarment J, David J$S$, Peyrefitte $S$ : Tactical damage control resuscitation in austere military environments. J R Army Med Corps 2016; 162(6): 419-27.

8. Albreiki M, Voegeli D. Permissive hypotensive resuscitation in adult patients with traumatic haemorrhagic shock: a systematic review. Eur J Trauma Emerg Surg. 2018; 44(2): 191-202.

Brain hypoxia is exacerbated in hypobaria during aeromedical evacuation in swine with traumatic brain injury. J Trauma Acute Care Surg 81(1): 101-7.

6. Skovira, J.W., Kabadi, S.V., Wu, J. et al (2016). Simulated aeromedical evacuation exacerbates experimental brain injury. J Neurotrauma. 33(14): 1292-302.

7. Daniel, Y., Habas, S., Malan, L., Escarment, J., David, J-S,. Peyrefitte, S. (2016). Tactical damage control resuscitation in austere military environments. J R Army Med Corps. 162(6): 419-27.

8. Albreiki, M., Voegeli, D. (2018). Permissive hypotensive resuscitation in adult patients with traumatic haemorrhagic shock: a systematic review. Eur J Trauma Emerg Surg. 44(2): 191-202.

\title{
ОЦЕНКА ИЗМЕНЕНИЙ ГЕМОДИНАМИКИ У ПОСТРАДАВШИХ ВОЕННОСЛУЖАЩИХ С МИННО-ВЗРЫВНЫМИ РАНЕНИЯМИ В ПРОЦЕССЕ АЭРОМЕДИЦИНСКОЙ ЭВАКУАЦИИ
}

\author{
Г.П. Хитрый, Ю.Д. Ухач
}

Украинская военно-медицинская академия, г. Киев, Украина.

Введение. Быстрая медицинская эвакуация путем аэроэвакуации в места оказания квалифицированной и специализированной медицинской помощи стала более эффективной со времен Второй мировой войны и признана эффективной в способности "очистки поля боя" и ускорения эвакуации пострадавших в больницы и клинические центры. Тем не менее, влияние аэромедицинской эвакуации на пациентов с политравмой все еще недостаточно ясен, особенно в случае массовой эвакуации, когда широкому кругу пациентов может понадобиться сортировка в сложных условиях или экстремальных условиях с ограниченной доступностью. 
Цель работы. Оценить гемодинамические изменения во время проведения аэромедицинской эвакуации у пострадавших с политравмой и с проникающими ранениями головы.

Материалы и методы. Проведен ретроспективный анализ карт интенсивной терапии 32 раненых и травмированных военнослужащих которым проводилась аэромедицинская эвакуация из зоны проведения АТО / ООС в течение 2017-2018 г2.

Результаты. На первом этапе исследования было установлено, что уровень САД на наземном этапе эвакуащии в группе с минно-взрывными проникающими ранениями головы составил 91,4 \pm 5,9 мм рт. ст. 8 то время как у пострадавших с минно-взрывными ранениями живота и / или грудной клетки он был значительно ниже и составлял 87,5 \pm 4,8 мм рт. cm.(p<0,05). Показатели пульса составляли 75,1 $\pm 4,7$ и 79,4 $\pm 5,1$ уд / мин. в исследуемых группах $(p<0,05)$. На втором этапе исследования установлено статистически достоверное снижение показателей гемодинамики и нарастания ЧСС у пострадавших обеих групп по сравнению с исходными данными. Так в 1-й группе САД составил 85,4 \pm 4,8 мм рт. ст., ЧСС 82,1 \pm 6,3 (p <0,05), а во второй - 82,7 \pm 4,9 мм рт. ст., ЧСС 86,2 $\pm 5,8$ ( $p<0,05)$. На последующих этапах (20 и 40 минута) аэромедицинской эвакуации постепенная стабилизация гемодинамики. На завершающем этапе эвакуации в обеих исследуемых группах показатели ЧСС и САД находились в пределах значений, полученных на наземном этапе

Выводы. В результате проведенного исследования установлено, что на втором этапе исследования (подъем на высоту) наблюдались достоверные изменения гемодинамических показателей, которые проявлялись гипотензией и тахикардией $(p<0,05)$, постепенно были медикаментозно корректированный, и начиная с 3 этапа (20 мин.) вернулись к исходным значениям в обеих исследуемых группах. В пострадавших из минно-взрывными ранениями живота и / или грудной клетки на 4-м этапе исследования наблюдалось снижение САД, что может указывать на более выраженную гемодинамическую неустойчивость в данной исследуемой группе.

Ключевые слова: аэромедицинская эвакуация, среднее артериальное давление, изменения гемодинамики.

\title{
ASSESSMENT OF HEMODYNAMIC CHANGES IN COMBAT CASUALTIESWITH MINE-EXPLOSIVE INJURIES IN THE PROCESS OF AEROMEDICAL EVACUATIONS
}

\author{
G.P. Khytryi, Yu.D. Ukhach
}

\author{
Ukrainian Military Medical Academy, Kyiv, Ukraine
}

Introduction. Rapid medical evacuation by air evacuation to skilled and specialized medical care facilities has become more effective since World War II and has been recognized as effective in being able to "clear the battlefield" and accelerate the evacuation of casualties to hospitals and clinical centers. However, the impact of aeromedical evacuation on patients with polytrauma is still poorly understood, especially in the case of mass evacuation when a wide range of patients may require sorting in harsh or extreme conditions with limited availability.

The purpose. Assess hemodynamic changes during aeromedical evacuation in victims with polytrauma and penetrating head injuries.

Materials and methods. A retrospective analysis of intensive care cards of 32 wounded and injured servicemen who were carried out by aeromedical evacuation from the area of anti-terrorist operation / joint force operation during 2017-2018.

Results.At the first stage of the study, it was found that the level of MAP at the ground stage of evacuations in the group with mine-explosive penetrating head injuries was $91.4 \pm 5.9 \mathrm{~mm} \mathrm{Hg}$, while in victims with mine-explosive injuries of the abdomen and / or chest, it was significantly lower and was $87.5 \pm 4.8 \mathrm{~mm} \mathrm{Hg}(p<0,05)$. Pulse rates were $75.1 \pm 4.7$ and $79.4 \pm 5.1 \mathrm{bpm}$. in the study groups, respectively $(p<0,05)$. In the second stage of the study, a statistically significant decrease in hemodynamics and heart rate in the affected groups was found compared to baseline. Thus, in the 1 st group MAP was $85.4 \pm 4.8 \mathrm{~mm} \mathrm{Hg}$, heart rate $82.1 \pm 6.3(p<0.05)$, and in the second $-82.7 \pm 4.9 \mathrm{~mm}$. Hg, heart rate $86.2 \pm 5.8$ ( $p$ <.05). In the subsequent stages (20 and 40 minutes) of aeromedical evacuation gradual stabilization of hemodynamics. At the final stage of evacuation in both study groups, heart rate and MAP were within the values obtained at the ground stage.

Conclusions. As a result of the study, it was found that in the second stage of the study (ascent) there were significant changes in hemodynamic parameters, which were manifested by hypotension and tachycardia $(p<0.05)$, which were gradually corrected, and starting from stage 3 (20 min.) returned to baseline values in both study groups. In victims with mine-explosive injuries of the abdomen and / or chest in the 4th stage of the study, a decrease in MAP was observed, which may indicate greater hemodynamic instability in this study group.

Key words: aeromedical evacuation, mean arterial pressure, changes in hemodynamics.

Конфлікт інтересів відсутній.

Conflict of interest: the authors have no conflict of interest to declare 


\section{Відомості про авторів:}

Хитрий Г.П., D E F - полковник медичної служби, доктор медичних наук, професор, начальник кафедри анестезіології та реаніматології Української військово-медичної академії, м. Київ, Україна;

Ухач Ю.Д., в С D - капітан медичної служби, ад’юнкт кафедри анестезіології та реаніматології Української військово-медичної академії, м. Київ, Україна

$A$ - концепція та дизайн дослідження; $B$-збір даних; $C$ - аналіз та інтерпретація даних;

$D$-написання статmi; $E$ - редагування статmi; $F$-остаточне затвердження статті.

\section{Сведения об авторах:}

Хитрый Г.П., D E F - полковник медицинской службы, доктор медицинских наук, профессор, начальник кафедры анестезиологии и реаниматологии Украинской военно-медицинской академии., Г. Киев, Украина;

Ухач Ю.Д., в с D - капитан медицинской службы, адъюнкт кафедры анестезиологии и реаниматологии Украинской военно-медицинской академии, г. Киев, Украина.

\section{Information about authors:}

Khytryi G.P., C D F - Colonel of Medical Service, Doctor of Medical Sciences, Professor, Chief of Department of Anesthesiology and Reanimatology of the Ukrainian Military Medical Academy, Kyiv, Ukraine. https://orcid.org/0000-0002-7888-1771.

Ukhach Yu.D., A B D - Captain of the Medical Service, Adjunct of the Department of Anesthesiology and Reanimatology Military Medical Academy, Kyiv, Ukraine.E-mail: yuraukhach@gmail.com, https://orcid.org/00000001-6566-042X.

$A$ - concept and design of the study; $B$ - data collection; $C$ - data analysis and interpretation;

$D$ - writing an article; $E$ - editing the article; $F$ - the final approval of the article.

Адреса для листування: вул. Московська, 45/1, буд. 33, м. Київ 01015 